\title{
The Association of Childhood Factors with Children's Subjective Well-Being and Emotional and Behavioural Difficulties at 11 years old
}

\author{
Gwyther Rees ${ }^{1}$
}

Accepted: 5 June 2017 / Published online: 28 June 2017

(C) The Author(s) 2017. This article is an open access publication

\begin{abstract}
Studies using cross-sectional data have found that factors such as family socio-economic status, family structure and parental well-being have relatively weak associations with children's subjective well-being. However there is a lack of longitudinal research exploring whether early childhood circumstances, and the cumulative effect of these kinds of factors over time, exert a stronger influence. This article uses data from a longitudinal representative sample of over 13,000 children in the UK to examine the associations between family and socio-economic factors from the age of nine months to 11 years old and children's subjective well-being at the age of 11 . The analysis finds that family and socio-economic factors in early and middle childhood only explain small amounts of the variation in children's subjective well-being. A parallel analysis finds that the same factors can explain much more of the variation in children's emotional and behaviour difficulties. These findings strengthen existing cross-sectional evidence on the lack of substantial socio-economic variation in children's subjective well-being and provide further the support for the distinction between correlates of positive and negative indicators of child well-being.
\end{abstract}

Keywords Subjective well-being $\cdot$ Emotional and behaviour difficulties $\cdot$ Early childhood $\cdot$ Longitudinal studies $\cdot$ Socio-economic variations

\section{Introduction}

There is a growing interest in subjective well-being as a possible measure of societal progress, to complement other measures such as GDP. Measures of subjective well-

Gwyther Rees

ReesGN@cardiff.ac.uk

1 Cardiff School of Social Sciences, Cardiff University, Second Floor, 1-3 Museum Place,

Cardiff CF10 3BD, UK 
being are now being included alongside objective measures in sets of indicators of quality of life, such as the OECD's Better Life Initiative (OECD 2011). It is argued that subjective well-being can be a useful tool for national and local policymakers in their efforts to improve the quality of lives of the populations with whom they are concerned (Diener 2000; O’Donnell et al. 2014; Seaford 2013). If subjective well-being research is to fulfil this vision it must produce findings that are policy-relevant - i.e. identify factors associated with people's level of subjective well-being that can potentially be influenced by policy - in addition to being theoretically rigorous and empirically robust (Dolan and Metcalfe 2012).

There is a developing body of evidence on factors affecting adults' subjective wellbeing. Genetics and personality play an important role in predicting people's subjective well-being (Steel et al. 2008). Factors such as income, unemployment, partnership status and physical health have also been found to explain significant variation in adult subjective well-being in the UK (Layard et al. 2014; Oguz et al. 2013). Events and changes in people's lives such as marriage, divorce, bereavement and having a child affect subjective well-being. It seems that the impact of these events on subjective wellbeing may only last for a few years (Suh et al. 1996), although there is evidence of a long-lasting effect of losing one's job (Clark et al. 2008; Clark and Georgellis 2013).

In comparison, less is known about the factors affecting children's subjective wellbeing, and most published studies are based on analysis of cross-sectional data. As is the case with adults, personality is associated with children's subjective well-being (Goswami 2013; Suldo et al. 2014) but it is not clear about the direction of causality. Traditional economic measures such as household income appear to play less of a role in explaining children's subjective well-being than adults', but more direct measures of children's experiences of material deprivation (not having access to basic items and experiences) have greater explanatory power (Main and Bradshaw 2012). Factors such as children's experiences of bullying and the quality of family relationships play a much bigger role in explaining variations in their subjective well-being than socioeconomic factors (Rees and Bradshaw 2016).

These findings contrast with the factors associated with other indicators of children's well-being such as mental health problems (McLaughlin et al. 2011; Reiss 2013) and cognitive development (Heckman 2006; Washbrook et al. 2014), where there is much stronger evidence of a socio-economic gradient. A recent analysis by Patalay and Fitzsimons (2016) using cross-sectional data relating to children aged 11 years old found that a set of variables covering individual, family and wider factors could explain a much greater proportion of the variation in children's mental health problems than in their subjective well-being. However, there is a shortage of longitudinal analysis of the factors associated with children's subjective well-being. Two exceptions are an analysis of data on children aged 11 to 15 in the UK (Robson 2010) which found that changes in family structure were linked with lower child subjective well-being; and an analysis by Powdthavee and Vernoit (2013) suggesting that parental unemployment tends to have a more negative effect on the happiness of older children than younger children.

This scarcity of longitudinal analysis is problematic because, while it seems clear from existing research that children's current family and economic circumstances are only weakly associated with their current subjective well-being, it is nevertheless possible that early childhood experiences, the persistence of disadvantage over lengthy periods of time during childhood, and change and instability in children's lives may 
affect their subjective well-being more substantially. For example, persistent socioeconomic disadvantage during early childhood has been found to be linked to poorer cognitive and behavioural outcomes in the early years (Dickerson and Popli 2016; Holmes and Kiernan 2013; Schoon et al. 2010; Washbrook 2010). These findings also extend into middle childhood (McLeod and Shanahan 1996) and into early adolescence (Melchior et al. 2010; Najman et al. 2010; Strohschein 2005). Improvements in socioeconomic status have also been found to be related to better child mental health outcomes (Costello et al. 2003). In contrast, there is no published analysis of the association between the context and circumstances of children's lives in early and middle childhood and their later subjective well-being. This is a major evidence gap. The analysis presented in this paper makes a unique contribution to the research literature by addressing this gap.

\subsection{Subjective Well-Being}

Subjective well-being is a person's evaluation and feelings of their own life, and is commonly considered to consist of cognitive and affective components (Diener 1984). The cognitive component is made up of people's satisfaction with their lives as a whole (and specific aspects of their lives). The affective component is sub-divided into positive and negative affect. There is considerable empirical evidence to support this tripartite model of subjective well-being although the nature of the relationship between the three components has still not been fully clarified (Busseri and Sadava 2011). Life satisfaction has been found to be more temporally stable than affective subjective well-being which fluctuates over the short term (Eid and Diener 2004). From a policy perspective this may make life satisfaction findings of greater interest than findings on affect.

\subsection{The Distinction between Positive Mental Health and Mental Illness}

An important conceptual and empirical issue is the distinction and overlap between measures of positive experience, such as subjective well-being, and mental illness. A key principle of the positive psychology tradition is that positive mental health is more than the absence of mental disorders (Seligman and Csikszentmihalyi 2000). Empirically there is substantial evidence to support this idea. Research with adults (Bergsma and Veenhoven 2011; Keyes 2005) has found that it is not uncommon to be happy or satisfied with one's life while also meeting diagnostic criteria for mental disorders and also that there are different correlates of mental illness and positive mental health. For example, Westerhof and Keyes (2010) found in a study of Dutch adults that older adults had fewer mental illness problems than younger adults but did not have better positive mental health. Some similar research has also been undertaken with children (Antaramian et al. 2010; Suldo and Shaffer 2008) although here, also, longitudinal evidence is lacking.

\subsection{Research Aims and Questions}

The analysis presented in this paper addresses the gap in longitudinal analysis on children's subjective well-being discussed earlier and explores the possibility that persistent disadvantage and/or instability in children's lives during early to mid- 
childhood may be associated with lower subjective well-being at the age of 11. As discussed above, there is evidence of the impact of early childhood circumstances, and cumulative factors across childhood, on other kinds of outcomes. The broad aim of the paper is to explore whether these factors impact on children's subjective well-being.

First of all it is important to acknowledge that earlier circumstances are likely to be correlated with current subjective well-being because many socio-economic factors have substantial stability. For example, disadvantage earlier in childhood will be associated with disadvantage at a later point in time. Children living in households with low income at nine months old will also be at greater than average risk of living in low-income households at the age of 11 years old. However this kind of indirect effect is not particularly specific to the study of subjective well-being and would apply equally to any outcome at the age of 11 which is associated with children's circumstances at that age.

The overall question to be addressed in this paper regards whether information about family and socio-economic circumstances earlier in childhood predicts children's current levels of subjective well-being, over and above the explanatory power of current circumstances. It is possible that this kind of additional impact may come about in at least two ways. First, children's experiences throughout childhood may affect their evaluations of their lives at the age of 11 years old. Thus, they may respond to subjective well-being question not only on the basis of current circumstances but also on the basis of how they feel about their childhood as a whole. Second, earlier experiences may have had a cumulative and lasting impact on children's lives such that it affects their current subjective well-being. For example, persistent poverty may have negatively affected children's peer relationships persistently throughout childhood so that their current quality of life is poorer than a child who has only recently experienced poverty. Fluctuations and instability in children's lives, such as frequent changes in family structure, may also have a lasting impact.

Having explored the extent to which earlier circumstances are associated with children's subjective well-being at the age of 11 years old, the steps in the analysis are then replicated using a measure of children's emotional and behavioural difficulties as the dependent variable. This is an approach that has already been used with crosssectional data by Patalay and Fitzsimons (2016). They found that a range of individual, family, social and wider environmental factors explained much more of the variance in children's mental illness than in their subjective well-being. There are two reasons why it is useful to compare findings for subjective well-being and emotional and behavioural difficulties. The first is that it can provide a check on the predictive potential of the independent variables used in the analysis. It is already established from previous research that such variables are significantly associated with emotional and behavioural difficulties. Thus, verifying this finding provides some indication of whether the weak associations generally found between socio-economic variables and subjective wellbeing are attributable to the lack of sufficiently discriminating independent variables. The second reason is that comparing findings for the two dependent variables can shed some light on the hypothesised distinction between subjective well-being and mental health problems discussed in Section 1.2. If there are marked differences between the two models then this supports the distinction.

Finally, some comment is necessary on the types of independent variables used in the analysis. UK research on other childhood outcomes has tended to focus on three 
categories of variables (see, for example, Sabates and Dex 2015) - contextual variables (e.g. family structure), distal variables (e.g. household income) and proximal variables (e.g. parental well-being). However, in terms of studying subjective well-being there are drawbacks to including proximal variables such as measures of parental well-being in that it is possible that there are shared genetic influences, shared environmental experiences and the possibility of reciprocal effects between child and adult well-being. In terms of reciprocity, Powdthavee and Vignoles (2008) found some evidence in a UK sample of an effect of child life satisfaction on father's mental distress one year later, as well as evidence of effects of parental mental distress on children's later life satisfaction. Thus it is not certain that measures of parental well-being can be regarded as unidirectional predictors of children's subjective well-being. For this reason I have not include such variables in the current analysis, and have focused on family and socioeconomic factors where the risk of reciprocal effects is minimal.

In view of the above discussion the article aims to answer the following research questions which address a substantial gap in current evidence on factors affecting children's subjective well-being:

1. To what extent do early childhood family and socio-economic factors predict children's subjective well-being at the age of 11, once current circumstances are taken into account?

2. To what extent do stability and change in children's family and socio-economic circumstances throughout childhood predict subjective well-being at the age of 11 ?

3. How do the findings from (1) and (2) compare with the extent to which childhood family and socio-economic factors predict children's emotional and behavioural difficulties at the age of 11 ?

\section{Method}

\subsection{Data Source}

The analysis is based on data from the Millennium Cohort Study (MCS) - a longitudinal study of children in the UK who were born in 2000 and 2001. The analysis uses data gathered from the first five waves of the study which were conducted when the child was around nine months old and three, five, seven and 11 years old. The MCS involved around 19,000 children, of which over 13,000 were still actively participating in Wave 5. A total of 13,469 child answered self-completion questionnaires in Wave 5. The analysis excludes second- and third-born children who were twins (168 cases) and triplets ( 7 cases), thus avoiding issues with clustering of small amounts of cases within households. This leaves a total of 13,287 children in different households. The research team who manage the study have paid careful attention to the effect of attrition on the representativeness of the study (Hansen 2014), and the survey data sets include weighting variables which can be used to balance the sample taking account of attrition.

The final sample used for analysis in this paper is smaller than the above total for three reasons. First, there is some missing data for the two dependent variables relating to subjective well-being and emotional and behavioural difficulties. A total of 1041 cases had missing data for one or both of these variables and are omitted from the 
analysis. Second, some of the households did not enter the study until Wave 2 and so initial data when the child was nine months old was not available. This led to a further 436 cases being omitted, which left a total of 11,810 cases to be included in the analysis. Cases excluded from this analysis differed somewhat at Wave 5 from those included - being less likely to live in households with both birth parents, less likely to live in England and more likely to be from low-income and minority ethnic backgrounds. This means that the analysis sample can not be regarded as wholly representative of the child population and this limitation should be borne in mind in interpreting the results. Finally, for those parts of the analysis that are based on summary measures across all five waves, it was only possible to include the 9634 children ( $72 \%$ of the total sample) for whom information was available for all waves. Children included in this analysis differed from those excluded in similar ways to that described above for the fuller analysis sample. Thus, the analysis using summary measures should not be taken to be generalisable to the child population in the UK in general. Despite this limitation the outcomes of the analysis are of some importance as they provide the first published evidence of the extent of association between children's circumstances in early and middle childhood and their later subjective well-being.

The use of imputation methods rather than omitting cases was considered. However imputation of dependent variables is not recommended (Von Hippel 2007) and imputation of complete waves of missing data in longitudinal analysis has been found to be of doubtful benefit for regression analysis (Young and Johnson 2015). There was very little missing data within available waves for the independent variables used and so there would be no great advantage in using imputation methods for data within waves.

The measures included in the analysis are drawn from the child self-completion questionnaire in Wave 5 and information provided by the main parent and derived variables (e.g. income) relating to the household as a whole in all available waves (as described above). The 'main parent' is the adult in the household who provides the most comprehensive set of information to the study. In Wave 5 of the survey, over $99 \%$ of the main parents were one of the child's birth parents, and $96 \%$ were female. The MCS also gathers information from the main parent's partner where relevant. This information has not been utilised in the analysis because, by Wave 5, many children only lived with one parent and also because partners may have moved in or out of the household during the five waves of the study, meaning that the partner information did not relate to the same person.

\subsection{Measures}

Two dependent variables were used to represent children's subjective well-being and emotional and behavioural difficulties at the age of 11. Relevant independent variables were selected which were available across all five waves of the MCS.

\subsubsection{Dependent Variable: Subjective Well-Being}

The Wave 5 child self-completion questionnaire includes six questions asking children how happy they are with their life as a whole and with specific aspects of their life family, friends, appearance, school and school work. Responses to these questions are on a seven-point bipolar scale where (in the questionnaire) a score of one is the most positive and a score of seven is the most negative. These questions do not specify a 
time scale and are of a broad evaluative nature. They are therefore taken to relate to cognitive subjective well-being. Some previous MCS analysis (e.g. Booker et al. 2015; Patalay and Fitzsimons 2016) has utilised a scale calculated by summing the answers to all six of these questions. However it is usual to view life satisfaction as being at a higher level of abstraction than domain satisfactions, which contribute to one's evaluation of one's life as a whole (Cummins 1996). Thus combining life satisfaction with domain satisfactions mixes two different levels of abstraction. Additionally, including two items relating to the school domain runs the risk that factors which are most strongly associated with children's school experience may tend to have a higher power than is warranted in predicting variations in subjective well-being.

In order to test the functioning of these items, confirmatory factor analysis was conducted using the lavaan package in R (Rosseel 2012), utilising robust (HuberWhite) estimators and standard errors due to the skewed nature of the variables and full information maximum likelihood estimation for missing data. ${ }^{1}$ The fit statistics for the six-item single-factor model the fit statistics were not fully acceptable (CFI $=0.941$; RMSEA $=0.090(0.086-0.093)$ ). Five-item models using only one of the two schoolrelated items were also tested and had poorer fit than the six-item model. However a four-item model consisting of happiness with family, friends, appearance and school had much better fit statistics $(\mathrm{CFI}=0.998, \mathrm{RMSEA}=0.023(0.015-0.031))$. This set of items also overcomes the conceptual problems highlighted above regarding mixing life satisfaction with domain satisfactions and is similar in make-up to four of the five domains of the Brief Multidimensional Student Life Satisfaction Scale developed and validated by Huebner et al. (2006). Thus a scale made up of these four items was used in the analysis. A score was created by summing the four items and then transforming the score so that the scale ran from zero to ten (for ease of interpretation) with a higher score representing higher subjective well-being.

\subsubsection{Dependent Variable: Emotional and Behavioural Difficulties}

The main parent questionnaire in Wave 5 of the MCS includes the parent version of the Strengths and Difficulties Questionnaire (SDQ). This is a widely used and validated measure (Goodman 1997) that can identify potential mental health problems in children and adolescents (Goodman et al. 2000). It is important to clarify that although this is often referred to as a measure of mental health problems (e.g. Goodman and Goodman 2012) it is more precisely a measure of emotional and behavioural difficulties and this term is therefore used throughout the analysis section of this article.

The analysis uses the 'total difficulties' score which is calculated from responses to 20 questions in the SDQ covering emotional symptoms, peer problems, conduct problems and hyperactivity/inattention. The score can range from zero to 40 where a higher score indicates greater difficulties. This score was divided by four for the analysis in this paper so that it covers the same zero to ten range as the subjective well-being variable with a higher score representing greater emotional and behavioural difficulties.

\footnotetext{
${ }^{1}$ This analysis used the full original sample of children aged 11 years old. However the same models were run including only the sample selected for the analysis in this article and the conclusions were the same.
} 


\subsubsection{Independent Variables}

Two indicators of household composition and four socio-economic indicators are used as independent variables in the analysis. These are based on information that was available consistently across all five waves of the study. Unfortunately, other potential socio-economic indicators such as material deprivation were not available in a consistent form across all study waves. First I will describe the variables that were constructed for each wave of the study. Then I will go on to described the creation of summary variables based on information across waves.

The data set has detailed information about household composition. Based on this information a variable was constructed for each wave to represent family structure with four possible values - two birth parents, lone birth parent, parent and step-parent/ partner and other. The total number of children in the household is also included in the analysis.

The four socio-economic indicators are used in the analysis relating to household poverty, parental employment, home ownership and parental education. The income measure was the OECD-equivalised household income quintile. Additionally, the poverty threshold of $60 \%$ of median income is utilised for one summary variable. Binary variables were used indicating whether a parent or step-parent (referred to for brevity as 'parent') in the household was in paid employment (referred to below as 'parental employment' or 'parental unemployment' as appropriate), and whether the household owned the property or not (referred to below as 'home ownership'). Finally, the parental education variable was the main parent's highest qualification at each interview.

For each of the above six variables relating to family structure and socio-economic factors, the next step was to create summary variables utilising all available data across the five waves. Three different ways of summarising particular aspects of children's circumstances were considered based on the existing literature on child subjective wellbeing and other outcomes. First, it is possible that the direction of change (improvement or deterioration) in children's circumstances over time may affect their subjective wellbeing. This possibility is illustrated by the findings from Costello et al. (2003) discussed earlier that improvements in socio-economic status were related to better child mental health outcomes. Second, it is possible that instability in children's situation may impact on their well-being, as evidenced by Robson's (2010) findings on the negative impact on older children's subjective well-being of a change in family structure. Third, it is possible that persistent disadvantage might have a cumulative impact on children's well-being in a similar way to the impact of persistent poverty on various child outcomes in a number of previous studies cited earlier (e.g. Dickerson and Popli 2016). Thus it is relevant to look at trends and fluctuations in, and the persistence of, disadvantage.

The calculation of summary variables for trends was relatively straightforward and involved using data from Waves 1 and 5 to create a summary of the direction of travel between nine months old and 11 years old. For household income this was calculated as the numerical change (positive or negative) in income quintile between Waves 1 and 5. Details of the summary trend variables for each factor are provided in shown in Table 1 . In terms of fluctuations, the number of changes in circumstances between consecutive waves was calculated for income quintile, 
Table 1 Descriptive statistics for summary variables

\begin{tabular}{|c|c|c|c|c|}
\hline Income & Mean & $\mathrm{SD}$ & Min & Max \\
\hline Count (poverty) & 1.26 & 1.71 & 0 & 5 \\
\hline Trend in quintile & 0.11 & 1.09 & -4 & 4 \\
\hline Fluctuation in quintile & 0.66 & 0.52 & 0 & 4 \\
\hline Unemployment & Mean & $\mathrm{SD}$ & Min & $\operatorname{Max}$ \\
\hline Count & 0.74 & 1.42 & 0 & 5 \\
\hline Fluctuation (no. of changes) & 0.36 & 0.74 & 0 & 3 \\
\hline Trend (Waves 1 to 5) & $\%$ & & & \\
\hline Employed to Employed & $77.6 \%$ & & & \\
\hline Employed to Unemployed & $6.3 \%$ & & & \\
\hline Unemployed to Employed & $8.8 \%$ & & & \\
\hline Unemployed to Unemployed & $7.2 \%$ & & & \\
\hline Home ownership & $\%$ & & & \\
\hline \multicolumn{5}{|l|}{ Count } \\
\hline Always owned & $55.0 \%$ & & & \\
\hline Mixture & $19.8 \%$ & & & \\
\hline Never owned & $25.2 \%$ & & & \\
\hline \multicolumn{5}{|l|}{ Trend (Waves 1 to 5 ) } \\
\hline Owned at both waves & $57.4 \%$ & & & \\
\hline Not owned to Owned & $8.6 \%$ & & & \\
\hline Owned to Not owned & $6.7 \%$ & & & \\
\hline \multirow[t]{2}{*}{ Not owned at both waves } & $27.3 \%$ & & & \\
\hline & Mean & $\mathrm{SD}$ & Min & $\operatorname{Max}$ \\
\hline Fluctuation (no. of changes) & 0.24 & 0.52 & 0 & 2 \\
\hline Academic qualification & $\%$ & & & \\
\hline Improvement & $11.8 \%$ & & & \\
\hline \multicolumn{5}{|l|}{ Family structure } \\
\hline \multicolumn{5}{|l|}{ Trend (Waves 1 to 5 ) } \\
\hline Both birth parents at both waves & $64.7 \%$ & & & \\
\hline Both to Lone & $14.8 \%$ & & & \\
\hline Both to Step & $6.8 \%$ & & & \\
\hline Lone to Both & $2.1 \%$ & & & \\
\hline Lone to Step & $3.4 \%$ & & & \\
\hline Lone parent at both waves & $7.4 \%$ & & & \\
\hline \multirow[t]{2}{*}{ Other pattern } & $0.7 \%$ & & & \\
\hline & Mean & $\mathrm{SD}$ & Min & $\operatorname{Max}$ \\
\hline Fluctuation (no. of changes) & 0.43 & 0.73 & 0 & 3 \\
\hline \multicolumn{5}{|l|}{ Number of children } \\
\hline Trend (Waves 1 to 5 ) & $\%$ & & & \\
\hline Fewer at Wave 5 & $6.9 \%$ & & & \\
\hline Same at both waves & $43.8 \%$ & & & \\
\hline \multirow[t]{2}{*}{ More at Wave 5} & $49.3 \%$ & & & \\
\hline & Mean & $\mathrm{SD}$ & Min & $\operatorname{Max}$ \\
\hline Fluctuation (no. of changes) & 0.89 & 0.90 & 0 & 4 \\
\hline
\end{tabular}


parental employment status, home ownership, family structure and number of siblings. In each case this variable represented a simple count from no changes to a maximum of four possible changes across the five waves. Fluctuations were not relevant for academic qualifications as these can only increase. Finally, a summary of indicator of persistence of disadvantage was calculated for the three socio-economic variables where this was relevant. This involved counts of the number of waves at which the household was in poverty, had no parents in employment and lived in rented housing. Because the distribution of the count of rented housing was highly concentrated at the two ends of the continuum, this variable was simplified to consist of three categories - Always owned, Never owned and a mixture of the two.

\subsubsection{Control Variables}

The child's sex, age in months at the time of the Wave 5 interview and ethnic origin (six-category classification), their country of residence within the UK at Wave 5 and the main parent's age at the child's birth are included as control variables in all models.

\subsection{Data Analysis}

The data analysis was undertaken in a number of steps. First, a cross-sectional regression model with subjective well-being as a dependent variable was estimated using only information available when the child was aged 11 years old (Wave 5). The purpose of estimating this model is to act as a reference model because the fundamental question addressed by the study is whether using historical information adds any predictive power over and above this cross-sectional approach. Next a similar model is estimated using only information available when the child was nine months old (Wave 1). This provides some insight into whether very early childhood circumstances have any predictive power when considered alone. The third model includes information available at both Waves 1 and 5. This then provides a test of whether information from early childhood adds any predictive power once information at 11 years old is taking into account. Finally, a fourth model is estimated which makes use of the cross-wave summary variables described above to explore the potential added effect of factors such as persistent poverty across the age range considered. For the comparative purposes discussed in Section 1.3 the same models are then estimated using the measure of possible mental health problems as the dependent variable.

The use of linear regression is common practice in studies of subjective well-being even though subjective well-being variables are often measured at an ordinal rather than interval level of measurement. Analysis by Ferrer-i-Carbonell and Frijters (2004) suggests that assuming ordinality or cardinality makes little difference to the outcomes of analysis in this context. As an additional check, the main regressions presented in Tables 2 and 4 were repeated using linear regression with a binary variable (see Hellevik 2009) and also logistic regression. There were no substantive differences in the results of the three approaches, with the same independent variables making a significant contribution to each model. Although most of the independent variables included in the models tended to be moderately correlated with one another, no 
Table 2 Regressions of children's subjective well-being onto single-wave variables

\begin{tabular}{|c|c|c|c|c|}
\hline & \multicolumn{2}{|c|}{ Model 1 (Wave 5) } & \multicolumn{2}{|c|}{ Model 2 (Wave 1) } \\
\hline & Coef. & {$[99 \% \mathrm{CI}]$} & Coef. & {$[99 \% \mathrm{CI}]$} \\
\hline Equiv. income quinti ${ }^{1}$ le (ref = Lowest) & 0.00 & {$[0.00,0.00]$} & 0.00 & {$[0.00,0.00]$} \\
\hline Second quintile & -0.02 & {$[-0.27,0.24]$} & 0.05 & {$[-0.13,0.24]$} \\
\hline Third quintile & -0.06 & {$[-0.36,0.24]$} & 0.10 & {$[-0.13,0.33]$} \\
\hline Fourth quintile & 0.04 & {$[-0.29,0.37]$} & 0.17 & {$[-0.08,0.41]$} \\
\hline Highest quintile & -0.00 & {$[-0.39,0.39]$} & $0.20 *$ & {$[-0.04,0.45]$} \\
\hline Household unemployment & -0.07 & {$[-0.27,0.14]$} & -0.02 & {$[-0.23,0.19]$} \\
\hline Owner occupied housing & $0.18 * *$ & {$[0.02,0.34]$} & $0.15^{*}$ & {$[-0.00,0.30]$} \\
\hline Parent's qualification (ref = None) & 0.00 & {$[0.00,0.00]$} & 0.00 & {$[0.00,0.00]$} \\
\hline NVQ Level 2 & 0.10 & {$[-0.12,0.31]$} & 0.07 & {$[-0.16,0.31]$} \\
\hline NVQ Level 3 & 0.06 & {$[-0.20,0.33]$} & 0.09 & {$[-0.19,0.36]$} \\
\hline NVQ Level 4 & 0.11 & {$[-0.14,0.36]$} & 0.09 & {$[-0.15,0.33]$} \\
\hline NVQ Level 5 & 0.03 & {$[-0.27,0.34]$} & 0.01 & {$[-0.33,0.34]$} \\
\hline Overseas qualification & 0.17 & {$[-0.24,0.59]$} & 0.15 & {$[-0.22,0.52]$} \\
\hline None of these & -0.01 & {$[-0.29,0.27]$} & 0.07 & {$[-0.24,0.37]$} \\
\hline Family type (ref = Both birth parents) & 0.00 & {$[0.00,0.00]$} & 0.00 & {$[0.00,0.00]$} \\
\hline Step & $-0.28 * *$ & {$[-0.49,-0.07]$} & -0.19 & {$[-1.28,0.89]$} \\
\hline Lone & $-0.30 * *$ & {$[-0.47,-0.13]$} & 0.02 & {$[-0.21,0.25]$} \\
\hline Number of children in home (ref $=$ One $)$ & 0.00 & {$[0.00,0.00]$} & 0.00 & {$[0.00,0.00]$} \\
\hline Two & -0.05 & {$[-0.22,0.12]$} & -0.07 & {$[-0.20,0.06]$} \\
\hline Three & -0.06 & {$[-0.28,0.17]$} & -0.02 & {$[-0.19,0.14]$} \\
\hline Four or more & -0.07 & {$[-0.34,0.19]$} & $-0.23 *$ & {$[-0.50,0.03]$} \\
\hline Constant & $6.48 * *$ & {$[4.43,8.53]$} & $6.20 * *$ & {$[4.17,8.22]$} \\
\hline Adjusted R squared & 0.0222 & 0.0163 & & \\
\hline Increase in $\mathrm{R}$ squared $\dagger$ & +0.0121 & +0.0042 & & \\
\hline $\mathrm{N}$ unweighted & 11,712 & 11,768 & & \\
\hline
\end{tabular}

$*=\mathrm{p}<0.05^{* *}=\mathrm{p}<0.01$ (bold) $\dagger$ Increase in R squared in comparison with a model with control variables only (adjusted $\mathrm{R}^{2}=0.0101$ )

All models also included the following control variables: child's age at Wave 5 in months, child's sex, child's ethnic group, country of residence at Wave 5 and mother's age at child's birth

problems with collinearity were identified (using the collin package in Stata) or through checking variance inflation factors with the models presented in the tables.

All analysis apart from the confirmatory factor analysis discussed earlier was undertaken using Stata 14. The MCS design over-samples children from disadvantaged and minority ethnic backgrounds. Weightings are provided in the data sets to take account of this and also to correct for the effects of sample attrition and these are used for all analysis. The analysis also utilises other information available in the data set to take account of the complex survey design (using svyset in Stata). Due to the large sample size, $p$-values less than 0.01 were treated as statistically significant and robust $99 \%$ confidence intervals are shown in the relevant statistical tables. 


\section{Results}

\subsection{Descriptive Statistics}

The distribution of the subjective well-being variable is fairly typical, being heavily skewed towards the positive end of the continuum (mean $=8.31$ on a 10 -point scale, s.d. $=1.84$, skewness $=-1.98$, kurtosis $=7.67$ ). Just over $5 \%$ of children scored below the mid-point of the scale indicating that they tended to be more unhappy than happy with the various aspects of their lives included in the measure. The distribution of the SDQ total difficulties score is also fairly typical (mean $=1.95$ on a 10 -point scale, s.d. $=1.47$, skewness $=1.19$, kurtosis $=4.52$ ) with around $6 \%$ of children scoring 19 or more on this measure indicating a high likelihood of mental health problems. The Pearson correlation between the two variables was -0.23 which was statistically significant but does not indicate a particularly strong cross-sectional association between children's subjective well-being and emotional and behavioural difficulties at the age of 11 years old.

Descriptive statistics for the summary variables are shown in Table 1. While many children in the sample experienced considerable stability in some or all aspects of their lives across this age range, there is also evidence of substantial change for many children. Around $70 \%$ of children did not change family structure across the five waves. This includes around $61 \%$ who always lived with both birth parents and around $9 \%$ who always lived with a lone parent. On the other hand only around $15 \%$ remained in the same income quintile across all five waves of the survey, around $11 \%$ were always below the poverty threshold and around 5\% of households had no parents in paid employment in any wave.

\subsection{Family and Socio-Economic Factors and children's Subjective Well-Being at 11 years old}

The results of three linear regression models using children's subjective well-being at the age of 11 as the dependent variable are shown in Table 2. Model 1 includes control variables plus independent variables at Wave 5 when the child is 11 years old and Model 2 instead includes independent variables relating to the same factors at Wave 1 when the child is around nine months old. The control variables which make a significant contribution to the models are ethnicity and country of residence. Children of Indian, Pakistani and Bangladeshi origin and those living in Wales and Northern Ireland had higher subjective well-being than the reference groups (children of White origin and children living in England respectively).

In Model 1, the family and socio-economic variables when the child was 11 years old that made a significant contribution to explaining variation in children's subjective well-being at that age were home ownership and family structure. Children living at 11 years old in rented housing had significantly lower subjective well-being than those living in housing owned by their family. Children living in a lone-parent or step-family had lower subjective well-being than those living with both birth parents. Thus, household income, parental employment status, parental education and the number of children in the household did not explain variation in children's subjective well-being.

Model 2 shows a similar regression model but using information on family and socioeconomic status when the child was nine months old rather than 11 years old. In this case, none of the six family and socio-economic factors at nine months old made a significant 
contribution to explaining variation in children's subjective well-being at the age of 11 years old. In view of this lack of significant associations it was not relevant to proceed with the next planned stage of the analysis and consider whether factors at nine months old had an any incremental explanatory power after controlling for the same factors at the age of 11 .

The second stage of the analysis was to run regressions of child subjective well-being at 11 years old onto the cross-wave summary variables described earlier. Initially this was done for each individual variable plus the control variables. Results are summarised in Table 3 which shows the regression coefficients with confidence intervals for each variable entered individually. The number of waves in which the household was below the poverty threshold was statistically significant. Children who lived in poverty at all five waves had mean life satisfaction scores 0.4 points lower on the 10 -point scale than children who had not lived in poverty at any of the waves. For parental unemployment it is notable that the number of changes in unemployment status over the five waves that made a significant contribution to explaining variations in child subjective well-being. Any experience of living in owned housing was associated with higher subjective wellbeing. Children who moved from living with both birth parents at Wave 1 to another family form at Wave 5 had lower mean subjective well-being, as did those who lived with lone parents at both waves, compared to children living with both birth parents at both waves. A larger number of fluctuations in family type were also associated with lower subjective well-being at the age of 11 .

The summary variable relating to each factor that made the most significant contribution (based on improvement in $\mathrm{R}^{2}$ ) in the above models were then entered into a combined regression as shown in Table 4. This selection of variables was necessary because of multicollinearity between different summary variables measuring the same factor. In this model, apart from some of the control variables, the only summary variable that made a significant contribution to the model (at the $99 \%$ confidence level) related to family structure. Children who moved from living with both birth parents at Wave 1 to living in a step or lone-parent family at Wave 5 had significantly lower subjective well-being than children who remained living with both birth parents. The explanatory power of this model was barely higher than Model 1 in Table 2 which only used contemporaneous data when the child was 11 years old. The one notable difference between these two models is that, when the summary variables are used, living with a lone parent, in itself, is not associated with lower child subjective well-being, although transitioning from a two-birth-parent family at nine months old to a lone-parent family at 11 years old is.

In summary, the findings of this analysis of family and socio-economic factors over the first 11 years of children's lives indicate that these factors do not explain substantial amounts of variation in children's subjective well-being, although they do provide some additional insights into the effect of family structure and structural change.

\subsection{Family and Socio-Economic Factors and children's Emotional and Behavioural Difficulties at 11 years old}

For comparison purposes the same analytical procedures described above were followed using the measure of emotional and behavioural difficulties as the dependent variable.

The regression models shown in Table 5 using control variables and data gathered at Wave 1 and at Wave 5 respectively (equivalent to the models in Table 2) confirmed previous findings on factors affecting children's emotional and behavioural difficulties. 
Table 3 Regression coefficients for each summary variable individually (plus control variables)

\begin{tabular}{|c|c|c|c|c|}
\hline & \multicolumn{2}{|c|}{ Subjective well-being } & \multicolumn{2}{|c|}{ Emotional and behavioural difficulties } \\
\hline \multicolumn{5}{|l|}{ Income } \\
\hline Count (poverty) & $-0.08 * *$ & {$[-0.13,-0.03]$} & $0.22 * *$ & {$[0.18,0.25]$} \\
\hline Trend in quintile & 0.00 & {$[-0.05,0.06]$} & -0.00 & {$[-0.04,0.03]$} \\
\hline Fluctuation in quintile & 0.01 & {$[-0.12,0.15]$} & 0.00 & {$[-0.09,0.10]$} \\
\hline \multicolumn{5}{|l|}{ Unemployment } \\
\hline Count & $-0.09 * *$ & {$[-0.15,-0.03]$} & $0.23 * *$ & {$[0.18,0.28]$} \\
\hline \multicolumn{5}{|c|}{ Trend (ref = Employed at both waves) } \\
\hline Employed to Unemployed & $-0.39 * *$ & {$[-0.67,-0.10]$} & $0.67 * *$ & {$[0.45,0.88]$} \\
\hline Unemployed to Employed & $-0.27 * *$ & {$[-0.53,-0.01]$} & $0.49 * *$ & {$[0.30,0.68]$} \\
\hline Unemployed to Unemployed & $-0.32 * *$ & {$[-0.62,-0.02]$} & $1.04 * *$ & {$[0.78,1.30]$} \\
\hline Fluctuation (no. of changes) & $-0.18^{* *}$ & {$[-0.28,-0.08]$} & $0.24 * *$ & {$[0.16,0.32]$} \\
\hline \multicolumn{5}{|l|}{ Home ownership } \\
\hline \multicolumn{5}{|l|}{ Count (ref = Always owned) } \\
\hline Mixture & $-0.21^{* *}$ & {$[-0.36,-0.06]$} & $0.37 * *$ & {$[0.24,0.49]$} \\
\hline Never owned & $-0.36^{* *}$ & {$[-0.52,-0.20]$} & $0.81 * *$ & {$[0.67,0.94]$} \\
\hline \multicolumn{5}{|c|}{ Trend (ref = Owned at both waves) } \\
\hline Not owned to Owned & -0.13 & {$[-0.34,0.08]$} & $0.35^{* *}$ & {$[0.18,0.53]$} \\
\hline Owned to Not owned & $-0.30 * *$ & {$[-0.54,-0.05]$} & $0.41^{* *}$ & {$[0.19,0.63]$} \\
\hline Not owned to Not owned & $-0.36^{* *}$ & {$[-0.52,-0.20]$} & $0.78 * *$ & {$[0.65,0.91]$} \\
\hline Fluctuation (no. of changes) & -0.07 & {$[-0.19,0.05]$} & 0.04 & {$[-0.05,0.12]$} \\
\hline \multicolumn{5}{|l|}{ Academic qualification } \\
\hline Improvement & -0.14 & {$[-0.33,0.06]$} & -0.01 & {$[-0.16,0.14]$} \\
\hline \multicolumn{5}{|l|}{ Family structure } \\
\hline \multicolumn{5}{|c|}{ Trend (ref $=$ Both birth parents at both waves) } \\
\hline Both to Lone & $-0.37 * *$ & {$[-0.55,-0.19]$} & $0.43 * *$ & {$[0.29,0.57]$} \\
\hline Both to Step & $-0.51^{* *}$ & {$[-0.79,-0.23]$} & $0.61 * *$ & {$[0.38,0.84]$} \\
\hline Lone to Both & -0.15 & {$[-0.65,0.35]$} & $0.45^{* *}$ & {$[0.09,0.80]$} \\
\hline Lone to Step & -0.23 & {$[-0.57,0.12]$} & $0.64 * *$ & {$[0.31,0.96]$} \\
\hline Lone to Lone & $-0.36^{* *}$ & {$[-0.69,-0.04]$} & $0.81 * *$ & {$[0.53,1.08]$} \\
\hline Other & -0.94 & {$[-2.20,0.32]$} & $1.016^{* *}$ & {$[0.29,1.83]$} \\
\hline Fluctuation (no. of changes) & $-0.23^{* *}$ & {$[-0.33,-0.12]$} & $0.24 * *$ & {$[0.16,0.33]$} \\
\hline \multicolumn{5}{|l|}{ Number of children } \\
\hline \multicolumn{5}{|l|}{ Trend (ref $=$ Fewer) } \\
\hline Same & 0.13 & {$[-0.12,0.38]$} & $-0.51^{* *}$ & {$[-0.71,-0.31]$} \\
\hline More & 0.22 & {$[-0.04,0.49]$} & $-0.59 * *$ & {$[-0.81,-0.37]$} \\
\hline Fluctuation (no. of changes) & -0.02 & {$[-0.09,0.05]$} & $0.08 * *$ & {$[0.03,0.13]$} \\
\hline
\end{tabular}

All models also included the following control variables: child's age at Wave 5 in months, child's sex, child's ethnic group, country of residence at Wave 5 and mother's age at child's birth

The control variables explained around 5\% of the variation in the measure of children's total difficulties scores at the age of 11 . Children who were female, older, and whose 
Table 4 Regressions of subjective well-being and emotional and behavioural difficulties at the age of 11 onto selected summary variables

\begin{tabular}{|c|c|c|c|c|}
\hline & \multicolumn{2}{|c|}{ Model A: Subjective well-being } & \multicolumn{2}{|c|}{$\begin{array}{l}\text { Model B: Emotional and } \\
\text { behavioural difficulties }\end{array}$} \\
\hline & Coef. & {$[99 \% \mathrm{CI}]$} & Coef. & {$[99 \% \mathrm{CI}]$} \\
\hline \multicolumn{5}{|l|}{ Poverty (no. of waves, ref. $=0$ ) } \\
\hline 1 & -0.01 & {$[-0.19,0.17]$} & $0.21 * *$ & {$[0.08,0.35]$} \\
\hline 2 & -0.11 & {$[-0.39,0.17]$} & $0.30 * *$ & {$[0.11,0.49]$} \\
\hline 3 & -0.06 & {$[-0.35,0.23]$} & $0.32 * *$ & {$[0.12,0.53]$} \\
\hline 4 & 0.10 & {$[-0.19,0.40]$} & $0.40 * *$ & {$[0.16,0.65]$} \\
\hline 5 & -0.11 & {$[-0.51,0.29]$} & $0.41 * *$ & {$[0.12,0.71]$} \\
\hline \multicolumn{5}{|c|}{ Unemployment (change from Waves 1 to 5 , ref. $=$ Employed to Employed) } \\
\hline Employed to Unemployed & -0.15 & {$[-0.46,0.16]$} & $0.30 * *$ & {$[0.06,0.54]$} \\
\hline Unemployed to Employed & -0.18 & {$[-0.51,0.15]$} & 0.04 & {$[-0.18,0.26]$} \\
\hline Unemployed to Unemployed & -0.14 & {$[-0.52,0.24]$} & $0.51 * *$ & {$[0.21,0.81]$} \\
\hline \multicolumn{5}{|c|}{ Home ownership (change from Waves 1 to 5 , ref. $=$ Both owned) } \\
\hline Not owned to Owned & -0.08 & {$[-0.29,0.14]$} & $0.21^{* *}$ & {$[0.04,0.37]$} \\
\hline Owned to Not owned & -0.12 & {$[-0.38,0.13]$} & 0.16 & {$[-0.07,0.38]$} \\
\hline Not owned to Not owned & $-0.18^{*}$ & {$[-0.38,0.03]$} & $0.30 * *$ & {$[0.15,0.45]$} \\
\hline \multicolumn{5}{|c|}{ Family type (change from Waves 1 to 5, ref. $=$ Both birth parents at both waves) } \\
\hline Both to Lone & $-0.26^{* *}$ & {$[-0.46,-0.07]$} & $0.17 * *$ & {$[0.01,0.33]$} \\
\hline Both to Step & $-0.46^{* *}$ & {$[-0.73,-0.18]$} & $0.46^{* *}$ & {$[0.24,0.67]$} \\
\hline Lone to Both & 0.05 & {$[-0.51,0.61]$} & 0.09 & {$[-0.28,0.47]$} \\
\hline Lone to Step & -0.03 & {$[-0.43,0.37]$} & $0.29 *$ & {$[-0.03,0.61]$} \\
\hline Lone to Lone & -0.15 & {$[-0.51,0.20]$} & $0.25^{*}$ & {$[-0.04,0.53]$} \\
\hline Other & -0.82 & {$[-2.06,0.41]$} & $0.71^{*}$ & {$[-0.07,1.50]$} \\
\hline Constant & $6.50 * *$ & {$[4.35,8.66]$} & $4.14 * *$ & {$[2.28,6.01]$} \\
\hline Adjusted $\mathrm{R}^{2}$ & 0.0237 & & 0.1223 & \\
\hline $\mathrm{N}$ unweighted & 9630 & & 9630 & \\
\hline
\end{tabular}

Model also includes the following control variables: child's age at Wave 5 in months, child's sex, child's ethnic group, country of residence at Wave 5 and mother's age at child's birth

main parent was aged 25 or over at the time of their birth had fewer emotional and behavioural difficulties. There was no significant variation according to ethnic group or country of residence.

Model 1 with control variables plus Wave 5 variables added around $7.5 \%$ explanatory power above that of the model with control variables. All of the family and socioeconomic variables made a significant contribution to the model. Higher income, higher parental educational qualifications, living in owner-occupied housing and having at least one parent in paid employment were all associated with fewer emotional and behavioural difficulties. Further, living in a lone-parent or step family at the age of 11 and being the sole child in the household was significantly associated with higher mental health problems. 
Table 5 Regressions of children's SDQ scores onto single-wave variables

\begin{tabular}{|c|c|c|c|c|}
\hline & \multicolumn{2}{|c|}{ Model 1 (Wave 5) } & \multicolumn{2}{|c|}{ Model 2 (Wave 1) } \\
\hline & Coef. & {$[99 \% \mathrm{CI}]$} & Coef. & {$[99 \% \mathrm{CI}]$} \\
\hline \multicolumn{5}{|c|}{ Equiv. income quintile (ref = Lowest) } \\
\hline Second quintile & -0.07 & {$[-0.29,0.14]$} & -0.05 & {$[-0.22,0.12]$} \\
\hline Third quintile & $-0.27^{* *}$ & {$[-0.53,-0.02]$} & $-0.21 * *$ & {$[-0.41,-0.00]$} \\
\hline Fourth quintile & $-0.43^{* *}$ & {$[-0.75,-0.12]$} & $-0.35^{* *}$ & {$[-0.55,-0.16]$} \\
\hline Highest quintile & $-0.49^{* *}$ & {$[-0.85,-0.13]$} & $-0.42^{* *}$ & {$[-0.62,-0.23]$} \\
\hline Household unemployment & $0.40 * *$ & {$[0.23,0.57]$} & $0.17^{*}$ & {$[-0.01,0.35]$} \\
\hline Owner occupied housing & $-0.14 *$ & {$[-0.30,0.02]$} & $-0.26^{* *}$ & {$[-0.36,-0.15]$} \\
\hline \multicolumn{5}{|c|}{ Parent's qualification ( $(\mathrm{ref}=$ None $)$} \\
\hline NVQ Level 2 & -0.02 & {$[-0.19,0.14]$} & -0.05 & {$[-0.22,0.13]$} \\
\hline NVQ Level 3 & -0.12 & {$[-0.32,0.09]$} & $-0.15^{*}$ & {$[-0.33,0.03]$} \\
\hline NVQ Level 4 & $-0.19^{*}$ & {$[-0.39,0.01]$} & $-0.29 * *$ & {$[-0.48,-0.10]$} \\
\hline NVQ Level 5 & $-0.19^{*}$ & {$[-0.43,0.04]$} & $-0.32 * *$ & {$[-0.53,-0.10]$} \\
\hline Overseas qualification & 0.06 & {$[-0.22,0.34]$} & -0.02 & {$[-0.34,0.31]$} \\
\hline None of these & $0.24 * *$ & {$[0.02,0.46]$} & 0.16 & {$[-0.08,0.40]$} \\
\hline \multicolumn{5}{|c|}{ Family type (ref = Both birth parents) } \\
\hline Step & $0.37 * *$ & {$[0.22,0.53]$} & 0.40 & {$[-0.34,1.15]$} \\
\hline Lone & $0.15^{* *}$ & {$[0.02,0.29]$} & 0.09 & {$[-0.10,0.28]$} \\
\hline \multicolumn{5}{|c|}{ Number of children in home $(\mathrm{ref}=$ One $)$} \\
\hline Two & $-0.14^{* *}$ & {$[-0.28,-0.01]$} & -0.06 & {$[-0.16,0.03]$} \\
\hline Three & $-0.16^{*}$ & {$[-0.33,0.01]$} & -0.01 & {$[-0.14,0.11]$} \\
\hline Four or more & $-0.23 * *$ & {$[-0.44,-0.03]$} & & \\
\hline Constant & $4.91 * *$ & {$[3.24,6.57]$} & $5.07 * *$ & {$[3.40,6.74]$} \\
\hline Adjusted R squared & 0.1298 & & 0.1123 & \\
\hline Increase in R squared* & +0.0755 & & +0.0580 & \\
\hline $\mathrm{N}$ unweighted & 11,712 & & 11,768 & \\
\hline
\end{tabular}

* Increase in $\mathrm{R}$ squared in comparison with a model with control variables only (adjusted $\mathrm{R}^{2}=0.0543$ )

All models also included the following control variables: child's age at Wave 5 in months, child's sex, child's ethnic group, country of residence at Wave 5 and mother's age at child's birth

The Wave 1 family and socio-economic variables in Model 2 added around 6\% to the explanatory power of the model with only control variables. Here only the four socio-economic variables, and not the two family structure variables, made a significant contribution. A model was also run with both Wave 1 and Wave 5 variables. Once Wave 5 and control variables are taken into account the only Wave 1 variable that made a significant contribution to the model was household income. The adjusted $\mathrm{R}^{2}$ for this model was $13.5 \%$. Thus introducing information about early childhood family and socio-economic circumstances only explained a very small amount of variation in children's emotional and behavioural difficulties at the age of 11 after accounting for characteristics and circumstances at that age.

This analysis is broadly consistent with the previous research findings on childhood factors associated with child mental health problems discussed in the introduction. The 
analysis indicates that these factors explain substantially more of the variation in children's emotional and behavioural difficulties at the age of 11 than they do in children's subjective well-being at the same age. Moreover, a substantial proportion (around 11\%) of the inequalities in the indicator of children's emotional and behavioural difficulties at the age of 11 can be predicted by their characteristics and the circumstances of their lives when they are nine months old.

The final column in Table 3 shows the contribution of each summary variable to explaining variation in children's emotional and behavioural difficulties at the age of 11. Most summary variables had statistically significant coefficients here. Finally, the same set of summary variables used to predict subjective well-being were included in a regression model with the SDQ total difficulties score as the dependent variable (Table 4. Model B). Here all four summary variables made a significant contribution to the model and the overall explanatory power was much higher than for subjective well-being (Model A).

In summary this analysis indicates that contemporaneous information about family and socio-economic factors can explain substantial amounts of the variation in an indicator of children's emotional and behavioural difficulties at the age of 11 and that information about these factors across earlier childhood can add modest explanatory power. Furthermore, the family and socio-economic factors considered in this analysis play a much bigger role in explaining variations in children's emotional and behavioural difficulties than in child subjective well-being.

\subsection{Summary of key Findings}

To conclude this section on results and to inform the discussion that follows, a summary of the explanatory power of each of the models tested above is provided in Table 6 which clearly illustrates the much stronger predictive power of both contemporaneous and historical family and socio-economic variables for emotional and behavioural difficulties at the age of 11 years old than for subjective well-being at the same age. For subjective well-being, it can be seen that, after taking account of control variables, none of the models provide more than a small increase in explanatory power. The contribution of including measures of family and socioeconomic factors throughout childhood $(+1.4 \%)$ is barely more than using contemporaneous information only $(+1.2 \%)$.

Table 6 A summary of the explanatory power of the different regression models

\begin{tabular}{lll}
\hline Model Independent variables & $\begin{array}{l}\text { Dependent variable } \\
\text { Subjective well-being }\end{array}$ & $\begin{array}{l}\text { Emotional and } \\
\text { behavioural difficulties }\end{array}$ \\
\hline Control variables & $1.0 \%$ & $5.4 \%$ \\
Wave 5 variables* & $2.2 \%$ & $13.0 \%$ \\
Wave 1 variables* & $1.6 \%$ & $11.2 \%$ \\
Wave 1 and 5 variables* & Not applicable & $13.5 \%$ \\
Wave 1 to 5 summary variables* & $2.4 \%$ & $12.2 \%$ \\
\hline
\end{tabular}

*All these models also included the following control variables: child's age at Wave 5 in months, child's sex, child's ethnic group, country of residence at Wave 5 and mother's age at child's birth 


\section{Discussion}

There is a growing interest in the study of subjective well-being, including children's subjective well-being. It is argued that subjective well-being measurement may have salience for public policy aimed at improving people's quality of life. Findings from cross-sectional data have provided insights into the correlates of children's subjective well-being. Yet there has been very little longitudinal analysis to explore the extent to which factors earlier in children's lives may be associated with their current levels of subjective well-being. This paper presents analysis which makes an important contribution to addressing this evidence gap. It utilises data from five waves of a large-scale UK longitudinal study to examine the extent to which early childhood factors, and the accumulation of factors over children's early and middle childhood can explain variations in their subjective well-being at the age of 11 years old. Analysis is also presented for a measure of children's emotional and behavioural difficulties at the age of 11 in order to provide a point of comparison with the findings on subjective well-being. The key messages from the analysis and implications of it are as follows.

\subsection{Key Messages and Implications}

Family and socio-economic variables, such as household income and family structure, measured when a child is nine months old only explain a very small amount of the variation in children's subjective well-being at the age of 11 years old. The same is true even when making use of summary measures of children's family and socio-economic circumstances at various points during childhood. Information about family and socioeconomic factors between the ages of nine months old and 11 years old does not add substantially to understanding variations in child subjective well-being at the age of 11 over and above what can be established cross-sectionally from children's circumstances at that age. This is an important conclusion. Prior research has tended only to utilise cross-sectional data and there has been a gap in evidence about whether early childhood factors, including cumulative adversities, can help to explain the variations that exist in children's subjective well-being in the way that they have done for educational outcomes (Caro et al. 2009; Crawford et al. 2015; Washbrook 2010) and mental health problems (Melchior et al. 2010; Najman et al. 2010; Strohschein 2005). While there are limitations to the current analysis (discussed below) this broad finding suggests that how children feel about their lives may be better understood by contemporaneous factors than historical ones.

It is rather remarkable that some of the socio-economic factors commonly associated with poorer 'outcomes' for children such as parental educational qualifications, parental unemployment and income poverty (including persistent poverty) appear to have so little association with children's subjective well-being. This is an important finding. If it is replicated in future analysis it would also draw a distinction between understandings of the drivers of children's subjective well-being and the drivers of other childhood outcomes where early childhood experiences and cumulative adversities seem to play an important part.

The findings from a parallel analysis of factors associated with children's emotional and behavioural difficulties at the age of 11 is consistent with other research on this topic cited above which indicates a stronger socio-economic gradient to these problems. 
The likelihood of emotional and behavioural difficulties at the age of 11 is significantly predicted by socio-economic factors including household income, parental unemployment, parental education and home ownership measured when a child is nine months old. The contrast in explanatory power of the models for the two dependent variables, using the same sample of children and the same independent variables, lends further weight to the conclusions just discussed for subjective well-being. It also supports previous studies discussed in the introduction (e.g. Keyes 2005) which have drawn a distinction between positive subjective well-being and mental health problems. The childhood factors associated with variations in children's emotional and behavioural difficulties at the age of 11 years old do not have the same predictive power in terms of how children evaluate or feel about their lives.

A more general message from the findings relates to the place that subjective wellbeing plays in the construction of indicators of 'well-being' in a broad sense. Children's subjective well-being is not strongly associated with objective indicators of family economic well-being; and it is not predicted by the same factors that predict other indicators of child well-being such as emotional and behavioural difficulties or educational attainment. One possible response to this 'lack of fit' of findings on children's subjective well-being is to omit children's evaluations of and feelings about their lives from conceptions of child well-being. However, dismissing children's views in this way is not in keeping with ideas of from the 'new' sociology of childhood (James and Prout 1997) regarding children as competent social actors or with the UN Convention on the Rights of the Child. It also does not acknowledge the considerable empirical work that has now been done to test and validate measures of children's self-reported well-being over the last few decades (e.g. Huebner 1991; Casas 2016). As concluded in a recent UNICEF Report Card 'Subjective well-being measures record something real and important about children's lives' (UNICEF 2013. p.43). Instead it seems important, as the above report suggests, to see children's own evaluations of their lives as a useful component of the overall concept of well-being, to be treated as complementary to other more objective indicators within a multi-dimensional framework of child well-being.

\subsection{Strengths and Limitations}

The analysis makes use of a recent and well-formulated longitudinal study of a representative sample of children in the UK. The size of the sample and the quality and range of the data available provides a valuable opportunity to explore the research questions posed in this paper. However some limitations of the analysis and possible directions for further research should be noted.

First, the subjective well-being questions contained within the child self-completion questionnaire are not entirely satisfactory. The four-item scale used for the analysis had acceptable fit using confirmatory factor analysis but some issues still remain. The response scales used are relatively short (seven options) and the domains covered do not represent a comprehensive set of the aspects of children's lives which are most important for their overall subjective well-being which might also include satisfaction with material circumstances, health, time use and so on (Rees et al. 2010). Ideally a multi-item context-free measure of cognitive subjective well-being such as Huebner's Student Life Satisfaction Scale (Huebner 1991) should be included in future research. 
Second, there are limitations to the range of factors for which there was information available at all five measurement points in the study. In particular, it was not possible to create summary measures of the quality and nature of parent-child relationships. This is a factor which has been linked cross-sectionally with variations in child subjective wellbeing (Rees and Bradshaw 2016) and future research might usefully explore this issue further if suitable longitudinal data are available.

Third, only one type of measure of poverty- based on household income - was included in this analysis. There is a growing recognition of the need for a multidimensional approach to defining and measuring child poverty (e.g. Bradshaw and Holmes 2010). Future research might also explore dimensions such as material deprivation and subjective experiences of poverty.

Finally, while the MCS sample is broadly representative and contains weightings to correct for issues such as sample attrition and over- and undersampling of different sub-groups, missing data for some of the key variables in the study within and across waves meant that the final analysis sample was not fully representative of the general child population. So some caution is needed in generalising the findings.

Acknowledgements The analysis on which this paper is based was undertaken as part of an ESRC-funded doctorate.

The author is grateful to The Centre for Longitudinal Studies, UCL Institute of Education for the use of the data analysed in this article and to the UK Data Archive and UK Data Service for making them available. However, these organisations bear no responsibility for the analysis or interpretation of these data.

Open Access This article is distributed under the terms of the Creative Commons Attribution 4.0 International License (http://creativecommons.org/licenses/by/4.0/), which permits unrestricted use, distribution, and reproduction in any medium, provided you give appropriate credit to the original author(s) and the source, provide a link to the Creative Commons license, and indicate if changes were made.

\section{References}

Antaramian, S. P., Huebner, E. S., Hills, K. J., \& Valois, R. F. (2010). A dual-factor model of mental health: Toward a more comprehensive understanding of youth functioning. American Journal of Orthopsychiatry, 80(4), 462-472. doi:10.1111/j.1939-0025.2010.01049.x.

Bergsma, A., \& Veenhoven, R. (2011). The happiness of people with a mental disorder in modern society. Psychology of Well-Being, 1(1), 1-6. doi:10.1186/2211-1522-1-2.

Booker, C. L., Skew, A. J., Kelly, Y. J., \& Sacker, A. (2015). Media use, sports participation, and well-being in adolescence: Cross-sectional findings from the UK household longitudinal study. American Journal of Public Health, 105(1), 173-179. doi:10.2105/AJPH.2013.301783.

Bradshaw, J., \& Holmes, J. (2010). Child poverty in the first five years of life. In K. Hansen, H. Joshi, \& S. Dex (Eds.), Children of the 21st century: The first five years (pp. 13-31). Bristol: The Policy Press.

Busseri, M. A., \& Sadava, S. W. (2011). A review of the tripartite structure of subjective well-being: Implications for conceptualization, operationalization, analysis, and synthesis. Personality and Social Psychology Review, 15(3), 290-314. doi:10.1177/1088868310391271.

Caro, D. H., McDonald, J. T., \& Willms, J. D. (2009). Socio-economic status and academic achievement trajectories from childhood to adolescence. Canadian Journal of Education, 32(3), 558-590.

Casas, F. (2016). Analysing the comparability of 3 multi-item subjective well-being psychometric scales among 15 countries using samples of 10 and 12-year-olds. Child Indicators Research. doi:10.1007 /s12187-015-9360-0.

Clark, A. E., \& Georgellis, Y. (2013). Back to baseline in Britain: Adaptation in the British household Panel survey. Economica, 80(319), 496-512. doi:10.1111/ecca.12007. 
Clark, A. E., Diener, E., Georgellis, Y., \& Lucas, R. E. (2008). Lags and leads in life satisfaction: A test of the baseline hypothesis. The Economic Journal, 118(529), F222-F243. doi:10.1111/j.1468-0297.2008.02150.x.

Costello, E. J., Compton, S. N., Keeler, G., \& Angold, A. (2003). Relationships between poverty and psychopathology: A natural experiment. Journal of the American Medical Association, 290(15), 20232029. doi:10.1001/jama.290.15.2023.

Crawford, C., Macmillan, L., Vignoles, A., \& others. (2015). When and why do initially high attaining poor children fall behind? Centre for Analysis of social Exclusion, LSE. Retrieved from http://sticerd.lse.ac. uk/dps/case/spcc/WP20.pdf

Cummins, R. A. (1996). The domains of life satisfaction: An attempt to order chaos. Social Indicators Research, 38(3), 303-328. doi:10.1007/BF00292050.

Dickerson, A., \& Popli, G. K. (2016). Persistent poverty and children's cognitive development: Evidence from the UK Millennium cohort study. Journal of the Royal Statistical Society: Series A (Statistics in Society), 179(2), 535-558. doi:10.1111/rssa.12128.

Diener, E. (1984). Subjective well-being. Psychological Bulletin, 95(3), 542-575. doi:10.1037/00332909.95.3.542.

Diener, E. (2000). Subjective well-being: The science of happiness and a proposal for a national index. American Psychologist, 55(1), 34-43.

Dolan, P., \& Metcalfe, R. (2012). Measuring subjective wellbeing: Recommendations on measures for use by National Governments. Journal of Social Policy, 41(2), 409-427. doi:10.1017/S0047279411000833.

Eid, M., \& Diener, E. (2004). Global judgments of subjective well-being: Situational variability and long-term stability. Social Indicators Research, 65(3), 245-277.

Ferrer-i-Carbonell, A., \& Frijters, P. (2004). How important is methodology for the estimates of the determinants of happiness? The Economic Journal, 114(497), 641-659. doi:10.1111/j.14680297.2004.00235.x.

Goodman, R. (1997). The Strengths and difficulties questionnaire: A research note. Journal of Child Psychology and Psychiatry, 38(5), 581-586. doi:10.1111/j.1469-7610.1997.tb01545.x.

Goodman, A., \& Goodman, R. (2012). Strengths and difficulties questionnaire scores and mental health in looked after children. The British Journal of Psychiatry, 200(5), 426-427. doi:10.1192/bjp. bp.111.104380.

Goodman, R., Ford, T., Simmons, H., Gatward, R., \& Meltzer, H. (2000). Using the Strengths and difficulties questionnaire (SDQ) to screen for child psychiatric disorders in a community sample. The British Journal of Psychiatry, 177(6), 534-539. doi:10.1192/bjp.177.6.534.

Goswami, H. (2013). Children's subjective well-being: Socio-demographic characteristics and personality. Child Indicators Research, 1-22. doi:10.1007/s12187-013-9205-7.

Hansen, K. (Ed.). (2014). Millennium cohort study: A guide to the datasets (eighth edition): First, second, third, fourth and fifth surveys. London: Centre for Longitudinal Studies.

Heckman, J. J. (2006). Skill formation and the economics of investing in disadvantaged children. Science, 312(5782), 1900-1902. doi:10.1126/science.1130121.

Hellevik, O. (2009). Linear versus logistic regression when the dependent variable is a dichotomy. Quality and Quantity, 43(1), 59-74. doi:10.1007/s11135-007-9077-3.

Holmes, J., \& Kiernan, K. (2013). Persistent poverty and children's development in the early years of childhood. Policy \& Politics, 41(1), 19-42. doi:10.1332/030557312X645810.

Huebner, E. S. (1991). Initial development of the Student's life satisfaction scale. School Psychology International, 12(3), 231-240. doi:10.1177/0143034391123010.

Huebner, E. S., Seligson, J. L., Valois, R. F., \& Suldo, S. M. (2006). A review of the brief multidimensional students' life satisfaction scale. Social Indicators Research, 79(3), 477-484. doi:10.1007/s11205-0055395-9.

James, A., \& Prout, A. (Eds.). (1997). Constructing and reconstructing childhood: Contemporary issues in the Sociological study of childhood. London: Falmer.

Keyes, C. L. M. (2005). Mental illness and/or mental health? Investigating axioms of the complete state model of health. Journal of Consulting and Clinical Psychology, 73(3), 539-548. doi:10.1037/0022-006 X.73.3.539.

Layard, R., Clark, A. E., Cornaglia, F., Powdthavee, N., \& Vernoit, J. (2014). What predicts a successful life? A life-course model of well-being. The Economic Journal, 124(580), F720-F738. doi:10.1111 /ecoj.12170.

Main, G., \& Bradshaw, J. (2012). A child material deprivation index. Child Indicators Research, 5(3), 503521. doi:10.1007/s12187-012-9145-7.

McLaughlin, K. A., Breslau, J., Green, J. G., Lakoma, M. D., Sampson, N. A., Zaslavsky, A. M., \& Kessler, R. C. (2011). Childhood socio-economic status and the onset, persistence, and severity of DSM-IV mental 
disorders in a US national sample. Social Science \& Medicine, 73(7), 1088-1096. doi:10.1016/j. socscimed.2011.06.011.

McLeod, J. D., \& Shanahan, M. J. (1996). Trajectories of poverty and Children's mental health. Journal of Health and Social Behavior, 37(3), 207. doi:10.2307/2137292.

Melchior, M., Chastang, J.-F., Walburg, V., Arseneault, L., Galéra, C., \& Fombonne, E. (2010). Family income and youths' symptoms of depression and anxiety: A longitudinal study of the French GAZEL youth cohort. Depression and Anxiety, 27(12), 1095-1103. doi:10.1002/da.20761.

Najman, J. M., Hayatbakhsh, M. R., Clavarino, A., Bor, W., O’Callaghan, M. J., \& Williams, G. M. (2010). Family poverty over the early life course and recurrent adolescent and young adult anxiety and depression: A longitudinal study. American Journal of Public Health, 100(9), 1719-1723. doi:10.2105 /AJPH.2009.180943.

O’Donnell, G., Deaton, A., Durand, M., Halpern, D., \& Layard, R. (2014). Wellbeing and Policy. London: Legatum Institute. Retrieved from http:/www.li.com/programmes/the-commission-on-wellbeing-and-policy

OECD. (2011). How's life? Paris: OECD Publishing.

Oguz, S., Merad, S., \& Snape, D. (2013). Measuring National Well-Being - what matters most to personal well-being? Newport: Office for National Statistics.

Patalay, P., \& Fitzsimons, E. (2016). Correlates of mental illness and wellbeing in children: Are they the same? Results From the UK Millennium Cohort Study. Journal of the American Academy of Child \& Adolescent Psychiatry, 55(9), 771-783. doi:10.1016/j.jaac.2016.05.019.

Powdthavee, N., \& Vignoles, A. (2008). Mental health of parents and life satisfaction of children: A withinfamily analysis of intergenerational transmission of well-being. Social Indicators Research, 88(3), 397422. doi:10.1007/s11205-007-9223-2.

Powdthavee, N., \& Vernoit, J. (2013). Parental unemployment and children's happiness: A longitudinal study of young people's well-being in unemployed households. Labour Economics, 24, 253-263. doi:10.1016 j.labeco.2013.09.008.

Rees, G. and Bradshaw, J. (2016). Exploring low subjective well-being among children aged 11 in the UK: An analysis using data reported by parents and by children. Child Indicators Research. Online First article. doi:10.1007/s12187-016-9421-z.

Rees, G., Goswami, H., \& Bradshaw, J. (2010). Developing an index of children's subjective well-being in England. London: The Children's Society.

Reiss, F. (2013). Socioeconomic inequalities and mental health problems in children and adolescents: A systematic review. Social Science \& Medicine, 90, 24-31. doi:10.1016/j.socscimed.2013.04.026.

Robson, K. (2010). Changes in family structure and the well-being of British children: Evidence from a fifteen-year Panel study. Child Indicators Research, 3(1), 65-83. doi:10.1007/s12187-009-9057-3.

Rosseel, Y. (2012). Lavaan: An R package for structural equation modeling. Journal of Statistical Software, 48(2), 1-36. doi:10.18637/jss.v048.i02.

Sabates, R., \& Dex, S. (2015). The impact of multiple risk factors on young Children's cognitive and Behavioural development. Children \& Society, 29(2), 95-108. doi:10.1111/chso.12024.

Schoon, I., Hope, S., Ross, A., \& Duckworth, K. (2010). Family hardship and children's development: The early years. Longitudinal and Life Course Studies, 1(3), 209-222. doi:10.14301/1lcs.v1i3.109.

Seaford, C. (2013). The multiple uses of subjective well-being indicators. Social Indicators Research, 114(1), 29-43. doi:10.1007/s11205-013-0381-0.

Seligman, M. E. P., \& Csikszentmihalyi, M. (2000). Positive psychology: An introduction. American Psychologist, 55(1), 5-14. doi:10.1037//0003-066X.55.1.5.

Steel, P., Schmidt, J., \& Shultz, J. (2008). Refining the relationship between personality and subjective wellbeing. Psychological Bulletin, 134(1), 138-161. doi:10.1037/0033-2909.134.1.138.

Strohschein, L. (2005). Household income histories and child mental health trajectories. Journal of Health and Social Behavior, 46(4), 359-375.

Suh, E., Diener, E., \& Fujita, F. (1996). Events and subjective well-being: Only recent events matter. Journal of Personality and Social Psychology, 70(5), 1091.

Suldo, S., \& Shaffer, E. (2008). Looking beyond psychopathology: The dual-factor model of mental health in youth. School Psychology Review, 37(1), 52-68.

Suldo, S. M., Minch, D. R., \& Hearon, B. V. (2014). Adolescent life satisfaction and personality Characteristics: Investigating Relationships Using a Five Factor Model. Journal of Happiness Studies. doi:10.1007/s10902-014-9544-1.

UNICEF Office of Research. (2013). Child well-being in rich countries: A comparative overview. In Innocenti report card 11. Florence: UNICEF Office of Research.

Von Hippel, P. T. (2007). Regression with missing Ys: An improved strategy for analyzing multiply imputed data. Sociological Methodology, 37(1), 83-117. doi:10.1111/j.1467-9531.2007.00180.x. 
Washbrook, E. (2010). Early environments and child outcomes: An analysis commission for the Frank Field MP independent review on poverty and life chances. London: Cabinet Office.

Washbrook, E., Gregg, P., \& Propper, C. (2014). A decomposition analysis of the relationship between parental income and multiple child outcomes. Journal of the Royal Statistical Society: Series A (Statistics in Society), 177(4), 757-782. doi:10.1111/rssa.12074.

Westerhof, G. J., \& Keyes, C. L. M. (2010). Mental illness and mental health: The two continua model across the lifespan. Journal of Adult Development, 17(2), 110-119. doi:10.1007/s10804-009-9082-y.

Young, R., \& Johnson, D. R. (2015). Handling missing values in longitudinal Panel data with multiple imputation. Journal of Marriage and Family, 77(1), 277-294. doi:10.1111/jomf.12144. 